\title{
Dynamic Characteristics Analysis of Threaded Connection Projectile Penetration
}

\author{
Ping Guan \\ Science and Technology on Electromechanical \\ Dynamic Control Laboratory \\ Beijing Institute of Technology \\ Beijing China \\ yiranhenzhun@163.com \\ Rong-chang Song \\ Science and Technology on Electromechanical \\ Dynamic Control Laboratory \\ Beijing Institute of Technology \\ Beijing China \\ bit_src@bit.edu.cn
}

\author{
Qing-sen Chen \\ Science and Technology on Electromechanical \\ Dynamic Control Laboratory \\ Beijing Institute of Technology \\ Beijing China \\ 1990chs@163.com \\ Geng-chen Shi \\ Science and Technology on Electromechanical \\ Dynamic Control Laboratory \\ Beijing Institute of Technology \\ Beijing China \\ Shigengchen@bit.edu.cn
}

\begin{abstract}
In this paper, the explicit finite element dynamic software LS-DYNA was utilized to investigate the process of projectile penetrating targets. The finite element model of projectile is simplified as two parts, warhead and balance part. In the finite element model, the threaded connection between warhead and balance part was set appropriately as contact. Projectile penetrated two or three target plates with different thicknesses, which are made of different materials. The results show that the contact between warhead and balance part fails in the penetration. After penetration, petal shaped crevasse appears on the target plate. While projectile penetrate the second or the last target plate, balance part may impact warhead after the failure of contact.
\end{abstract}

Keywords- finite element analysis; penetration; projectile; threaded connection; dynamic characteristics

\section{INTRODUCTION}

With the rapid development of computer technology, Computer Aided Engineering (CAE) has been widely applied in the field of engineering technology [1-3]. As the most widely used numerical method, finite element method (FEM) [4] has been utilized to investigate the process of penetration and high velocity impact [5-9].LSDYNA is a kind of explicit dynamic software and can simulate the process of projectile penetrating target plates [10-11].

There have already been some studies about penetration [12-14]. However, most of these studies simplify the projectile as a whole, and there is only one target plate. In this paper, the finite element model of projectile is simplified as a two parts, warhead and balance part. And the contact type between warhead and balance part was set appropriately to simulate the threaded connection. Projectile penetrated two or three target plates with different size, which are made of different material.

\section{NUMERICAL MODELLING}

The model of one kind of projectile is shown in Fig .1. This projectile is made up of two parts, warhead and balance part. They are connected by thread. Warhead is made of high strength material. Balance part is used to balance the projectile.

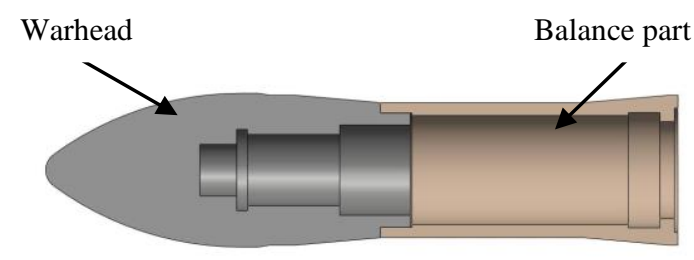

Figure 1. Model of Projectile

\section{A. Simulation Environment}

Positions of target plates are shown in Fig .2. Fig .3 is the model of projectile and target plates. The materials and thickness of each target plate in different situations are shown in Tab. I .The projectile has two initial velocities, $600 \mathrm{~m} / \mathrm{s}$ and $700 \mathrm{~m} / \mathrm{s}$.

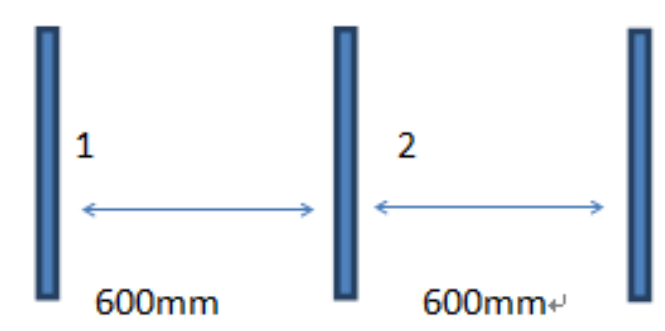

Figure 2. Model of Target Plates 
TABLE I. TAget Plates' Properties Of DifFerent Conditions

\begin{tabular}{|c|c|c|c|c|c|c|c|c|}
\hline \multirow{2}{*}{ Condition } & \multicolumn{3}{|c|}{ a } & \multicolumn{3}{c|}{ b } & \multicolumn{2}{c|}{ c } \\
\cline { 2 - 9 } & Target Plate1 & Target Plate2 & Target Plate3 & Target Plate1 & Target Plate2 & Target Plate3 & Target Plate1 & Target Plate3 \\
\hline Material & 7A04AL & Q235Steel & 7A04AL & Q235Steel & Q235Steel & Q235Steel & Q235Steel & Q235Steel \\
\hline $\begin{array}{c}\text { Thickness } \\
(\mathrm{mm})\end{array}$ & 12 & 12 & 12 & 12 & 12 & 12 & 20 & 12 \\
\hline
\end{tabular}

TABLE II. Major Material Parameters On Plastic_Kinematic Model

\begin{tabular}{|c|c|c|c|c|c|c|}
\hline Material & $\mathbf{\rho}(\mathbf{g} / \mathbf{c m} 3)$ & $\mathbf{E}(\mathbf{G P a})$ & $\boldsymbol{\mu}$ & $\mathbf{A}(\mathbf{G P a})$ & $E_{t}(\mathbf{G P a})$ & Failure Strain \\
\hline 30CrMnSiA & 7.93 & 204 & 0.30 & 3.36 & 79.38 & 0.45 \\
\hline 7A04AL & 2.85 & 509 & 0.33 & 5.85 & 8.75 & 0.15 \\
\hline
\end{tabular}

TABLE III. MAJOR MATERIAL PARAMETERS ON JOHNSON-COOK MODEL

\begin{tabular}{|r|l|l|l|l|c|c|}
\hline Material & $\mathbf{\rho}\left(\mathbf{g} / \mathbf{c m}^{3}\right)$ & $\mathbf{G}(\mathbf{G P a})$ & $\mathbf{E}(\mathbf{G P a})$ & $\boldsymbol{\mu}$ & $\mathbf{A}(\mathbf{M P a})$ & $\mathbf{B}(\mathbf{M P a})$ \\
\hline Q235Steel & 7.85 & 79 & 200 & 0.3 & 507 & 320 \\
\hline Material & $\mathbf{N}$ & $\mathbf{C}$ & $\mathbf{M}$ & $\mathbf{T}_{\mathbf{m e l t}}(\mathbf{K})$ & $\mathbf{C}_{\mathbf{p}}\left(\mathbf{J} /\left(\mathbf{k g}^{\mathbf{2}} \mathbf{K}\right)\right)$ \\
\hline Q235Steel & 0.28 & 0.06 & 4.0 & 1793 & $\mathbf{P}_{\mathbf{c}}\left(\mathbf{g} \cdot \mathbf{c m}^{-1} \cdot \boldsymbol{\mu} \mathbf{s}^{-2}\right)$ \\
\hline
\end{tabular}

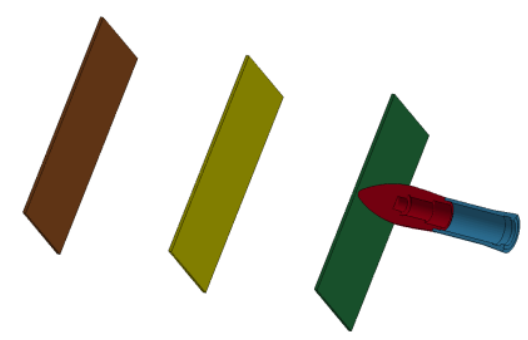

Figure 3. MOdel of Projectile and Target Plates

\section{B. Material Model}

The material of warhead and balance part is 30CrMnSiA-GB/T3077-1999, and we use PLASTIC_KINEMATIC material model in the simulations. Target Plates are made of two kinds of materials, 7A04Al and Q235Steel. The material model for target plates made of 7A04Al is PLASTIC_KINEMATIC, and for target plates made of Q235Steel is JOHNSON_COOK. The material properties are listed in Tab. II and Tab.III.

\section{Setting Contact for Threaded Connection}

In the finite element analysis, we use the contact type *CONTACT_TIEBREAK_SURFACE_TO_SURFACE

( TSTS ) to simulate the threaded connection between warhead and balance part.

Tiebreak contact is identical to tied contact except that the contact nodes (surfaces) are tied to the target surfaces only until a failure criterion is reached (Fig .4). This is done by 'pinning' the contact nodes (surfaces) to the target using a penalty stiffness; after the failure criterion is exceeded, the contact nodes (surfaces) are allowed to slide relative to, or separate from, the target surface. The tiebreak contact options are typically used to represent spot-welded or bolted connections. The main difference between TNTS and TSTS is that the TSTS failure is based on a failure stress and the TNTS is based on a failure force. When using TSTS, the normal (V1) and shear (V2) failure stresses must be specified.

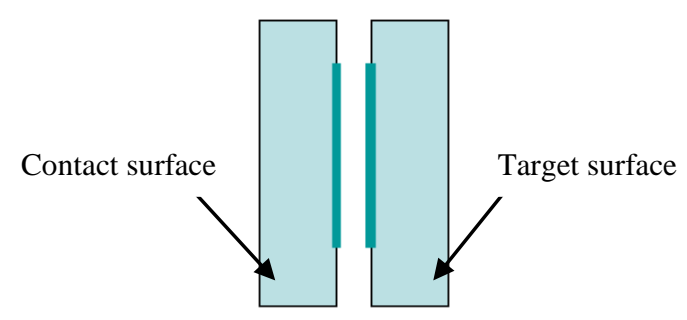

Figure 4. Model of Contact Surface and Target Surface

Failure of the connection will occur when:

$$
\left[\frac{\left|f_{n}\right|}{f_{n_{1} \text { fail }}}\right]^{m_{1}}+\left[\frac{\left|f_{s}\right|}{f_{s_{1} \text { fail }}}\right]^{m_{2}} \geq 1
$$

$f_{n}$ is the normal failure stress, and $f_{s}$ is the shear failure stress.

The normal failure stress of threaded connection is $765 \mathrm{MPa}$, and the shear failure is $400 \mathrm{MPa}$.

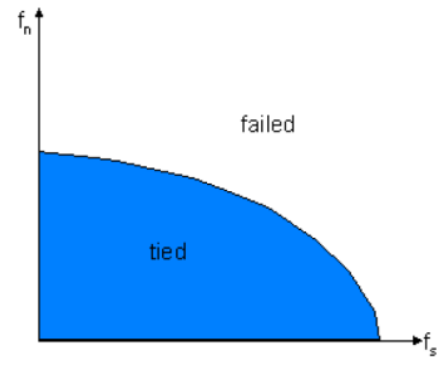

Figure 5. Failure Criterion

The connection between warhead and balance part is shown in Fig .6.

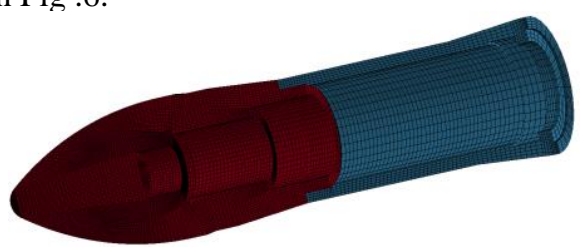

Figure 6. The Connection between Warhead and Balance Part 


\section{RESULTS}

By the code ANSYS/LS-DYNA, processes of penetration under different conditions have been simulated.

In the condition $\mathrm{b}$, for example, projectile penetrated target plates with the initial velocity $700 \mathrm{~m} / \mathrm{s}$. Fig .7-Fig .9 are mises stress nephograms of warhead, balance part and target plates.

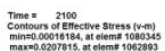

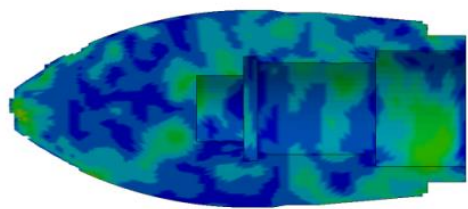

Figure 7. Mises Stress Nephograms of Warhead

The max mises stress of warhead is $24.94 \mathrm{GPa}$ in the process of penetration.

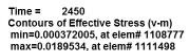

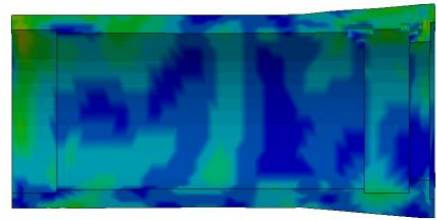

Figure 8. Mises Stress Nephograms of Balance Part

The max mises stress of balance part is $8.58 \mathrm{GPa}$ in the process of penetration.

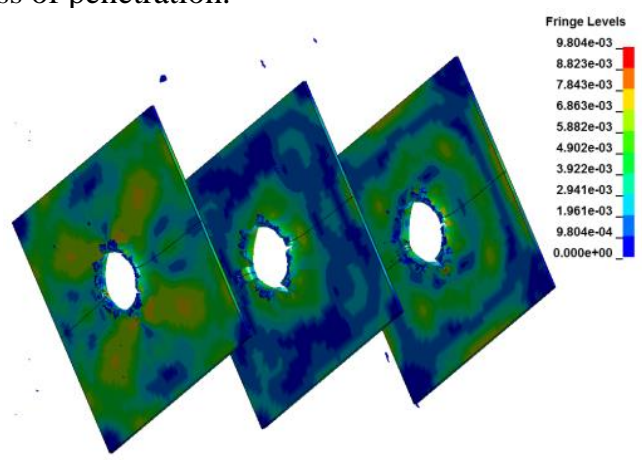

Figure 9. Mises Stress Nephograms of Targets Plates

There are petal shaped crevasse on the target plates because of the penetration. The penetration will reduce projectile's velocity, so the petal shaped crevasse on the first target plate is curliest in the process of penetration, and the crevasse on the second target plate is curlier than the crevasse on the last target plate.

Velocities of warhead and balance part are shown in Fig .10.

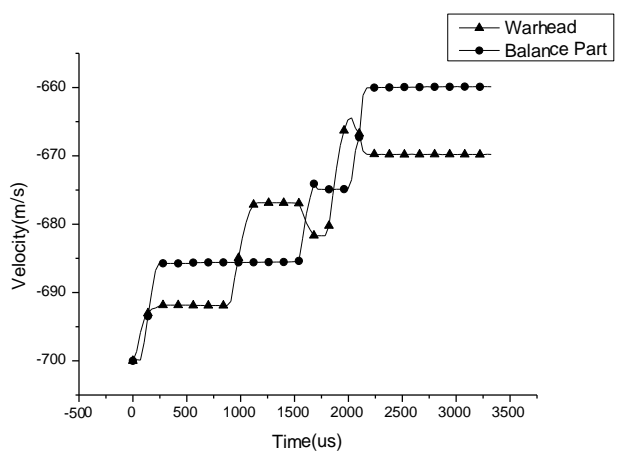

Figure 10. Figure 10. Velocities of Warhead and Balance Part

It's indicated in Fig .8 that balance part's velocity is reduced by target plates for penetrations. But after the first penetration, the velocities of two parts have been different, and while the second and the last penetration, the velocity of warhead has been increased because of collisions between warhead and balance part. The threaded connection was failed in the process of penetration.

Accelerations of warhead and balance part are shown in Fig .11.

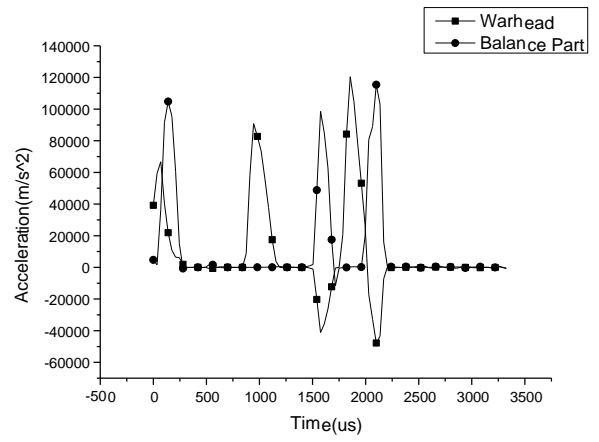

Figure 11. Accelerations of Warhead and Balance Part

Fig .9 shows that the peak of overload on warhead when the projectile penetrates the first target plate is about $7000 \mathrm{~g}$, and its pulse width is about $0.25 \mathrm{~ms}$. The peak of overload on balance part when the projectile penetrates the first target plate is about $10000 \mathrm{~g}$, and its pulse width is about $0.25 \mathrm{~ms}$.

The peak of overload on warhead when the projectile penetrates the second target plate is about $9000 \mathrm{~g}$, and its pulse width is about $0.3 \mathrm{~ms}$, but then a reverse overload, whose peak is about $4000 \mathrm{~g}$ and pulse width is about $0.2 \mathrm{~ms}$, appears because there is a collision between warhead and balance part. The peak of overload on balance part when the projectile penetrates the second target plate is about $10000 \mathrm{~g}$, and its pulse width is about $0.2 \mathrm{~ms}$.

The peak of overload on warhead when the projectile penetrates the last target plate is about $12000 \mathrm{~g}$, and its pulse width is about $0.25 \mathrm{~ms}$, but then a reverse overload, whose peak is about $5000 \mathrm{~g}$ and pulse width is about $0.25 \mathrm{~ms}$, appears because there is a collision between warhead and balance part again. The peak of overload on balance part when the projectile penetrates the last target plate is about $11500 \mathrm{~g}$, and its pulse width is about $0.25 \mathrm{~ms}$. 


\section{DISSCUSSION}

Fig .12 shows the relative velocities of warhead and balance part in the processes of penetration with different initial velocities under different conditions.

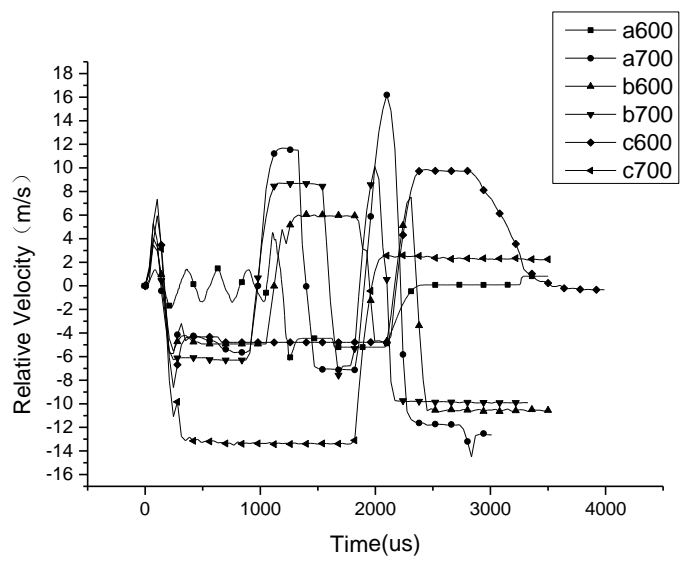

Figure 12. Relative Velocities of Warhead And Balance Part

Fig .13 shows the accelerations of warhead in the processes of penetration with different initial velocities under different conditions.

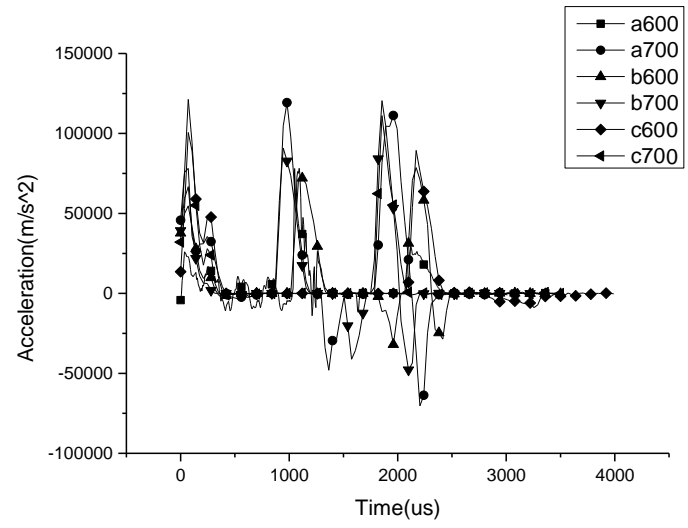

Figure 13. Accelerations of Warhead

Fig .14 shows the accelerations of balance part in the processes of penetration with different initial velocities under different conditions.

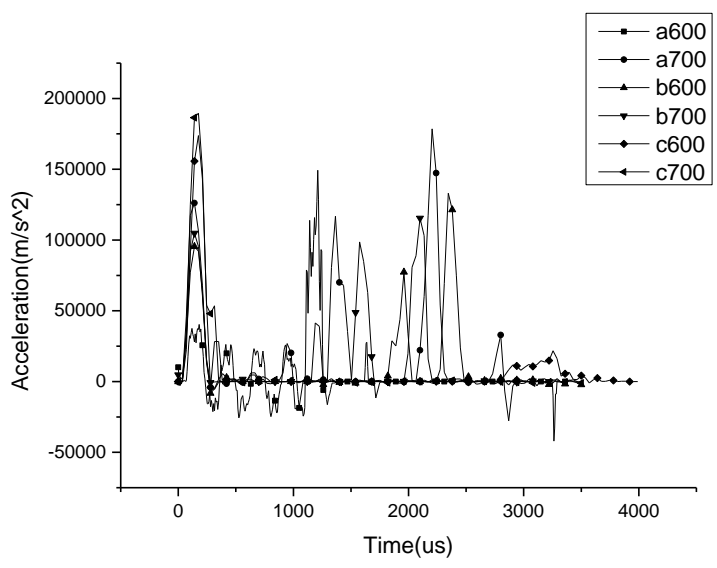

Figure 14. Accelerations of Balance Part
From above content, we can make the following analysis:

( 1 ) Under condition of a and b, the threaded connection failed after projectile penetrated the first target plate, and then there were two collisions between warhead and balance part.

(2) Under condition of $\mathrm{c}$, the threaded connection failed after projectile penetrated the first target plate, but there was no collision between warhead and balance part because the distance between warhead and balance part is too long.

\section{CONCLUSION}

In this paper, projectile penetrated two or three target plates with different thicknesses, which are made of different material. Projectile's initial velocity can be $600 \mathrm{~m} / \mathrm{s}$ or $700 \mathrm{~m} / \mathrm{s}$.

The results in the present investigation can be summarized as follows:

(1)When projectile penetrates target plates, the threaded connection will fail. Then the warhead and the balance part will separate from each other, but the balance part will impact the warhead when the warhead penetrates next target plate.

(2)After penetration, there will be petal shaped crevasse on the target plates. Target plates will reduce projectile's velocity.

(3)Warhead and balance part will continue to move forward.

\section{REFERENCES}

[1] C. P. Qu, "Computer-aided Engineering (CAE) Technology and Its Prospects," Computer Knowledge and Technology, vol. 9, Dec. 2013, pp. 8105-8106.

[2] D. N. Yang, J. X. Zou, "Research on CAE and Its Development," Mechanics and Practice, vol. 27, Jun. 2005, pp. 7-15.

[3] S. Q. Shi, ANSYS/LS-DYNA's Application in Engineering Field of Explosion and Impact, Beijing: China Building Industry Press, 2011.

[4] R. X. Li, Finite Element Method Basis, Beijing: National Defense Industry Press, 2002.

[5] Q. X. Xu, J. Z. Huang, R. Y. Shen, "Simulation of Penetration Test of Armoured Plate," vol. 25, Feb. 2006, pp. 117-119.

[6] R. Yang, "The Numerical Simulation and Ana1ysis for Deceleration Characteristic of the Ammunition into Conerete Targets," North University of China, 2009.

[7] X. M. Duan, Y Zhou, D. C. Jia, "Finite Element Analysis of Kinetic Energy Armour-piercing Process," Ordnance Material Science and Engineering, vol. 25, Nov. 2002, pp.20-22.

[8] J. Q. Huang, W. Zhang, L. Sun, "Numerical Simulation of Armourpiercing Warhead Penetration Process," Journal of System Simulation, vol. 21, Oct. 2009, pp. 6415-6417.

[9] J. Q. Wu, H. Z. Wang, "General Procedure For Analysis of Axial Response of Prismatic," Journal of Vibration and Shock, vol. 23 Nov. 2004, pp.101-104

[10] T. He, ANSYS10.0/LS-DYNA Nonlinear Finite Element Analysis Tutorial with Examples, Beijing: China Machine Press, 2007.

[11] H. O. Zhao, LS-DYNA Guidance of Dynamic Analysis, Beijing: Weapons Industry Press, 2003.

[12] C. Yang, B. R. Zhao, K. Q. Fu and Y. L. Wang, "Research for the relations between residual speed and target thickness," Ordnance Material Science and Engineering, vol. 26, Nov. 2003, pp. 3-5.

[13] C. H. Zhang, F. C. Wang, S. K. Li, "Numerical Simulation on Penetration Process of Tungsten Fiber Composite Penetrators," Rare Metal Materials and Engineering, vol. 32, Jun. 2003, pp.440442 . 
[14] D. W. Wang, H. Q. Gao, H. X. Du and S. L. Wang, "The Analysis and Simulation of Penetrating Movement of Oblique Projectile,"
Journal of Projectiles, Rockets, Missiles and Guidance, vol.26, Mar. 2006, pp. 121-123. 